\title{
PROJETO PADRINHOS NO PERÍODO LETIVO SUPLEMENTAR DA ESCOLA POLITÉCNICA DE PERNAMBUCO - AVALIAÇÃO DO ESTUDANTE INGRESSANTE
}

DOI: 10.37702/2175-957X.COBENGE.2021.3640

Paloma Silva de Melo - melopaloma0701@gmail.com

Universidade de Pernambuco

Av. Guararapes 706

53140-060 - Olinda - PE

ANNA LÚCIA MIRANDA COSTA - annalucia@poli.br

UNIVERSIDADE DE PERNAMBUCO

RUA BENFICA 455

50720-001 - RECIFE - PE

Manoela Pessoa - Mlabp@poli.br

Universidade de Pernambuco

rua major breno assis da silva 20

53150-210 - olinda - PE

Sânya Albuquerque de Araújo - sanya.araujoo@gmail.com

Universidade de Pernambuco

AV COLIBRI QUADRA 61 BLOCO 07 APTO 307115

53441-110 - PAULISTA - PE

Thays Marques Ferreira - thaysfmarques@gmail.com

Universidade de Pernambuco

Rua Barão de Mauá 541

53140-280 - Olinda - PE

Resumo: $O$ artigo apresenta um estudo da trajetória dos ingressantes da Escola Politécnica da Universidade de Pernambuco no Período Letivo Suplementar (PLS). Através da viabilização do Projeto Padrinhos foi possível realizar o estudo que objetiva identificar aspectos avaliados pelo estudante ingressante caracterizadores de seu desempenho acadêmico durante o PLS. De caráter exploratório, a pesquisa contemplou o uso de um formulário, que foi disponibilizado de forma online por 
meio da plataforma 'Google Forms'. Participaram 91 ingressantes que optaram por matricular-se nas disciplinas ofertadas pelos respectivos cursos de engenharia. As questões que mobilizaram o formulário foram estruturadas em 5 categorias: dados pessoais, disciplinas cursadas, comunicação, adaptação e aproveitamento. Como resultados: 29 ingressantes correspondem ao sexo feminino, enquanto 62 são do sexo masculino; em relação as disciplinas cursadas, obteve-se que 64 ingressantes efetivaram matrícula no mínimo em 4 disciplinas; observa-se ainda que 53 ingressantes registraram uma comunicação eficaz com a turma e os docentes; e que 51 ingressantes avaliaram positivamente a adaptação ao estilo das aula remotas; em conformidade ao aproveitamento acadêmico, 45 ingressantes conceituaram de modo satisfatório as disciplinas vivenciadas e 59 ingressantes avaliaram de forma proveitosa as disciplinas cursadas. Mesmo com o pioneirismo e a particularidade do PLS, esse estudo indica um aproveitamento satisfatório do período letivo, apesar de considerado como desafiador. Quanto a viabilização do Projeto Padrinhos em um contexto de distanciamento físico, a coordenação constata sua relevância por canalizar esforços dos veteranos envolvidos em garantir o acolhimento, a integração e a orientação ao ingressante.

Palavras-chave: Acolhimento. Desempenho acadêmico. Ingressantes. Integração. Período Letivo Suplementar. 


\section{PROJETO PADRINHOS NO PERÍODO LETIVO SUPLEMENTAR DA ESCOLA POLITÉCNICA DE PERNAMBUCO - AVALIAÇÃO DO ESTUDANTE INGRESSANTE}

\section{INTRODUÇÃO}

Com a instauração da pandemia da COVID-19 em março de 2020, os múltiplos sistemas de valores sociais, éticos, econômicos e até mesmo psicológicos foram afetados. Em função dos efeitos da pandemia, sublinhou-se ainda mais a importância da educação e da ciência como atividade integral no desenvolvimento do ser humano. A partir desse contexto, surgiu a necessidade de buscar alternativas para melhor atender às demandas resultantes da necessidade do resguardo e isolamento social. Educadores das mais diversas áreas do conhecimento se dedicaram ao tema centrados na ressignificação do ato educativo e no novo 'saberfazer' remoto (MARTINS; ALMEIDA, 2020; VIEIRA; RICCI, 2020).

Com o intento de manter a qualidade de ensino acadêmico sem perder o olhar sobre a condição do alunado e do professorado, a Universidade de Pernambuco (UPE) adotou um novo formato de ensino. A implantação de um Período Letivo Suplementar (PLS), assim como um formato de aulas remotas, foram fundamentais para retomada das atividades da graduação e da pós-graduação. Comprometida com este escopo, a Universidade de Pernambuco atendeu às diretrizes acadêmicas designadas pelo Conselho de Ensino, Pesquisa e Extensão - CEPE e o Conselho Universitário CONSUN da Universidade de Pernambuco sob o propósito de reafirmar o compromisso assumido com os estudantes, a citar, principalmente, os novos ingressantes do período letivo vigente naquele momento (UPE, 2020).

Enquanto uma das dezenove Unidades de Educação da UPE, a Escola Politécnica de Pernambuco (POLI) também ressignificou o planejamento de ensino dos sete cursos de engenharia e um de Física de Materiais, que oferta. Por já contar com um Núcleo de Apoio Psicopedagógico Inclusivo (NAPSI), tornou-se mais fácil pensar e implantar ações de acolhimento ao estudante durante o período remoto. Com este sentido e centrando o olhar sobre o estudante ingressante, o NAPSI viabilizou a realização do Projeto Padrinhos para acolher e auxiliar os estudantes que estavam experienciando seu primeiro contato com a universidade, em um momento adverso ao que se estimava como rotina.

As ações propostas pelo Projeto Padrinhos, entre outras bases teóricas, se fundamentam nos pressupostos relacionados ao desenvolvimento das competências socioemocionais, compreendendo-as como conjunto de habilidades emocionais, comportamentais e sociais (ZAMBIANCO, 2020). A partir desta perspectiva teórica, a coordenação do Projeto Padrinho reconhece a relevância em promover mecanismos de integração favorecedores de alguns domínios comprometidos com o desenvolvimento da inteligência emocional: empatia, motivação e autoconhecimento (GOLEMAN, 2012; ZAMBIANCO, 2020).

Por outro lado, encontra-se entre as considerações da coordenação do Projeto que a permanência do estudante no Ensino Superior e seu efetivo desempenho acadêmico estão integralmente relacionados ao desempenho e experiências vividas no primeiro ano de ingresso na universidade. Desta forma, fica ainda mais evidente a importância do papel desempenhado pelo Projeto que busca monitorar e amenizar o impacto gerado pela transição entre a Educação Básica e o Ensino Superior com ações integrativas, acolhedoras e orientadoras. 
As diretrizes tomadas pelo Projeto, mediante 0 isolamento social $e \quad 0$ desenvolvimento do PLS, expressaram a disposição de melhor acompanhar e identificar os aspectos que caracterizam o desenvolvimento acadêmico do estudante no período remoto. Com esta intenção, o artigo versa sobre estes resultados e objetiva, a partir dos 'achados', subsidiar a criação de novas estratégias que contribua para a efetiva integração do estudante ingressante que sejam favorecedoras de um bom desempenho acadêmico.

\section{PROCEDIMENTO METODOLÓGICO}

O presente estudo é de caráter quantitativo e exploratório por usar como base opiniões de um universo amostral que o represente de forma estatística (MANZATO; SANTOS, 2012). Com o propósito de cumprir o objetivo do projeto, os dados foram obtidos através de um questionário online, devido a facilidade de acesso da maior parte dos ingressantes e da possibilidade de obter respostas mais precisas.

Para a participação da pesquisa, foram convidados os ingressantes que participaram do PLS dos sete cursos de Engenharia oferecidos por a POLI/UPE. Nessa instituição, o ingresso dos estudantes do curso de Física de Materiais acontece no segundo semestre letivo de cada ano e por essa razão não possuía ingressantes de tal curso durante o período remoto, consequentemente não participaram deste presente estudo. A amostra desta pesquisa foi de 91 ingressantes, os mesmos tiveram acesso ao questionário na plataforma digital 'Google Forms', no período de 19 a 30 de março de 2021.

Para subsídios desta pesquisa, foram analisadas 7 perguntas e os dados obtidos foram armazenados, estudados e tratados por meio da plataforma Microsoft Office Excel (versão 2104). Os gráficos também foram obtidos por essa plataforma. Os dados foram organizados em cinco categorias de análise: dados pessoais, disciplinas cursadas, comunicação, adaptação e aproveitamento.

Quadro - Categorias de análise

\begin{tabular}{|l|l|}
\hline Categorias & Indicadores \\
\hline Dados pessoais & Representa o sexo e o curso \\
\hline Disciplinas cursadas & Quantidade de disciplinas cursadas \\
\hline Comunicação & $\begin{array}{l}\text { Comunicação com os professores e colegas } \\
\text { em função das atividades propostas }\end{array}$ \\
\hline Adaptação & Adequação a forma das aulas remotas \\
\hline Aproveitamento & $\begin{array}{l}\text { Aproveitamento das disciplinas vivenciadas } \\
\text { e o desempenho das mesmas }\end{array}$ \\
\hline
\end{tabular}

Fonte: Autor (2021)

\section{RESULTADOS E DISCUSSÕES}

Os resultados serão apresentados em razão das categorias definidas e apresentadas no Quadro 1. 


\subsection{Dados pessoais}

Acerca da temática do perfil do estudante das engenharias no Brasil, se evidencia uma participação feminina minoritária, visto que nesses cursos existem tradicionalmente a predominância do sexo masculino (RICOLDI; ARTES, 2016). O Censo da Educação Superior de 2018 (INEP, 2020) apresenta resultados frente a essa temática, evidenciando que entre os vinte cursos de graduação com números de matrículas mais expressivos, existe maior aparição feminina em quatorze dos mesmos. Quatro dos outros seis cursos com menos mulheres, pertencem ao curso de engenharia.

É a partir do contexto apresentado que se deve avaliar a Figura 1, correspondente a relação entre o curso e sexo. Observa que o quantitativo de ingressantes do sexo feminino é menor comparado ao do sexo masculino em todos os cursos. Ainda, salientase que de forma geral o quantitativo, em percentual, do sexo feminino corresponde a $31,86 \%$. Ao refletirmos essa temática a respeito dos cursos, é possível observar que Engenharia Civil apresenta uma menor desproporção entre os sexos feminino e masculino. Além disso, Engenharia Eletrônica, Telecomunicações, Mecânica e Computação registram os índices mais baixos de presença do sexo feminino. Diante desses dados observados, para a equipe de coordenação do projeto, os mesmos não aturdem visto que essa conjuntura é registrada em trabalhos antecedentes (NETO, 2020).

Figura 1: Relação entre o curso e sexo

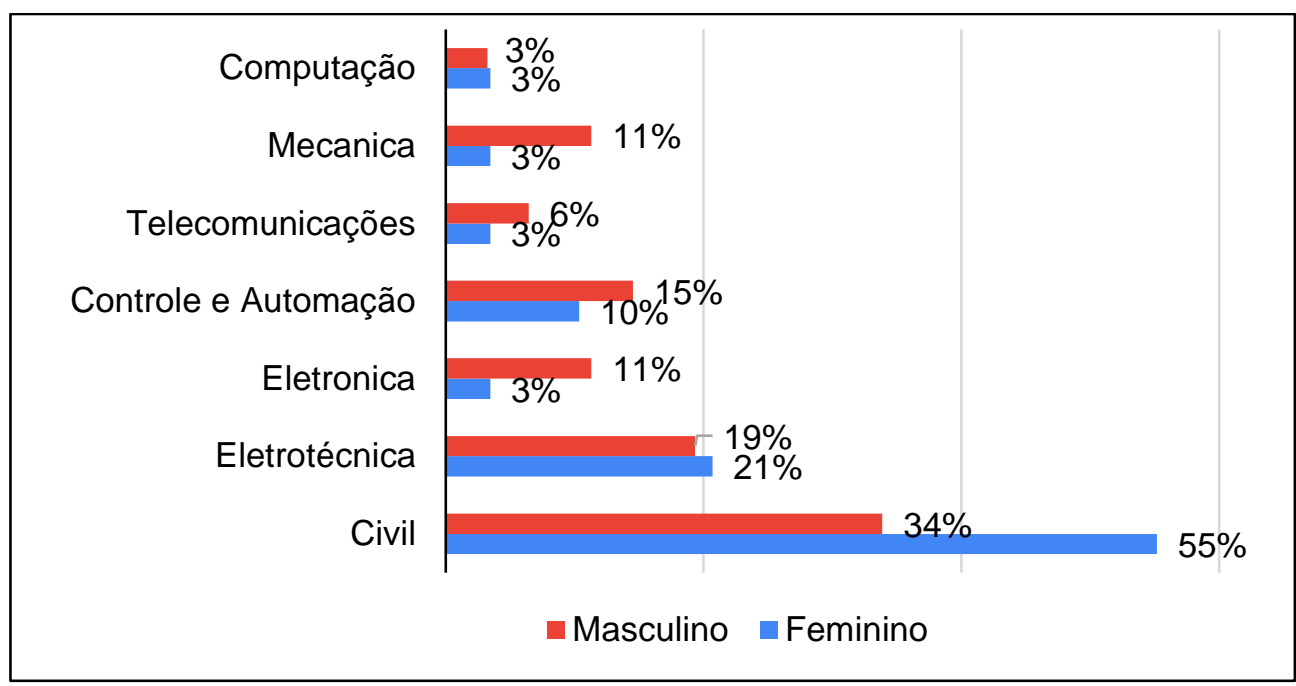

Fonte: Autor (2021).

\subsection{Disciplinas cursadas}

O período remoto proposto por o PLS oportunizou os discentes a cursarem as disciplinas no ano de 2020, registrando-as no histórico escolar em caso de aproveitamento. Além disso, a Resolução CEPE N 058/2020 adota o PLS e institui o limite de 240 horas em componentes curriculares cursados (UPE, 2020). 
Relacionado a esse tema, na Figura 2 pode-se analisar a quantidade de disciplinas cursadas por parte dos ingressantes. A mesma afirma que $70,32 \%$ dos ingressantes que cursaram o PLS, realizaram matrícula em 4 disciplinas ou mais (70,32\%). Ao debruçar a respeito dos dizeres da resolução citada no parágrafo anterior, pertinente a carga horária, verificou-se que $92,30 \%$ dos ingressantes cursaram no mínimo a metade da carga horária permitida.

Figura 2: Quantidade de disciplinas cursadas no PLS

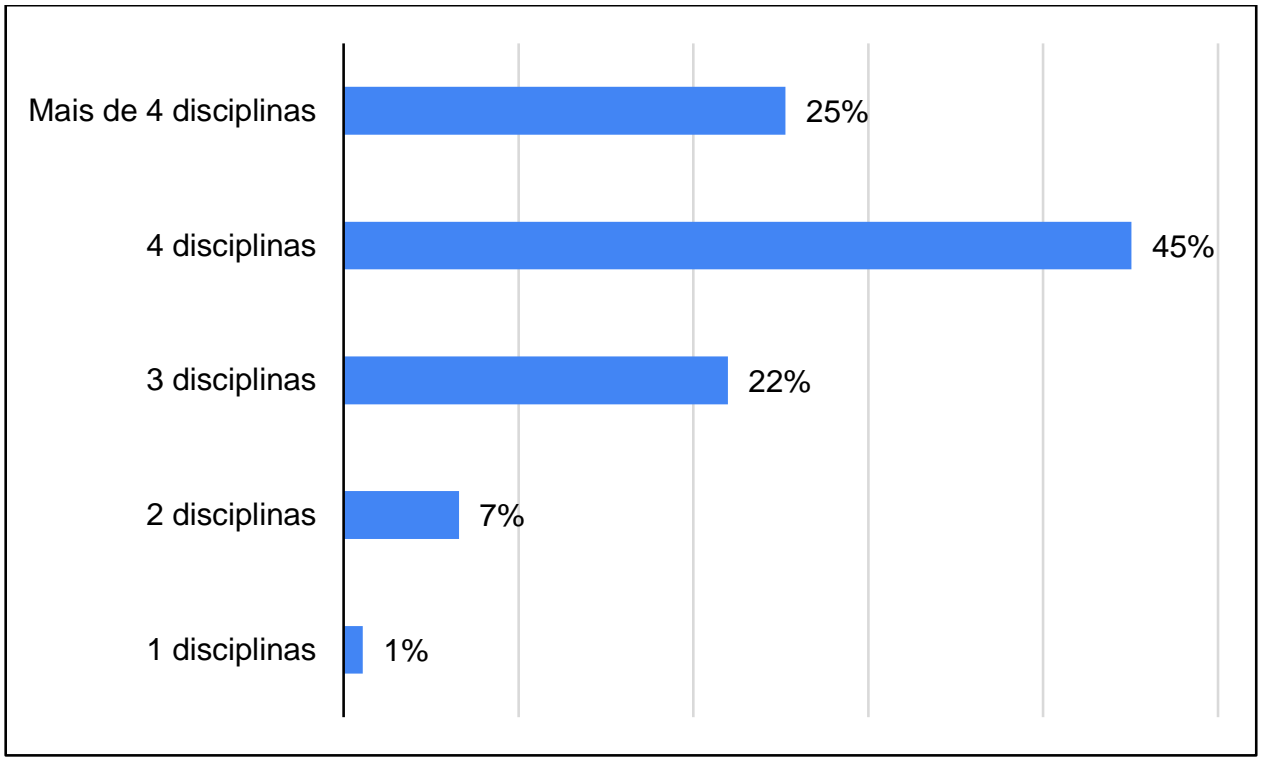

Fonte: Autor (2021).

\subsection{Comunicação com os professores e colegas}

A comunicação proposta no PLS referente às aulas remotas difere do habitual no período presencial, visto que a 'tradicional' comunicação presencial cedeu espaço ao uso de ferramentas e plataformas digitais. Diante desse fato, a POLI/UPE intensificou o uso da plataforma Moodle, através da criação de um ambiente virtual de aprendizagem (AVA), denominado de 'Poli Virtual', local esse em que professores e alunos puderam se comunicar e acompanhar o andamento das disciplinas, além do uso do e-mail institucional.

A partir dos dados obtidos em referência a comunicação durante o PLS na Figura 3 , pode ser identificado que $58,24 \%$ dos ingressantes consideraram "Ótimo e Bom", o que retrata o êxito no 'diálogo' satisfatório e positivo durante o desenvolvimento do Período Letivo Suplementar. Ressalta-se, ainda, que apenas $14,28 \%$ avaliaram a comunicação sendo "Ruim e Péssimo".

Figura 3: Avaliação da comunicação com os professores e colegas 


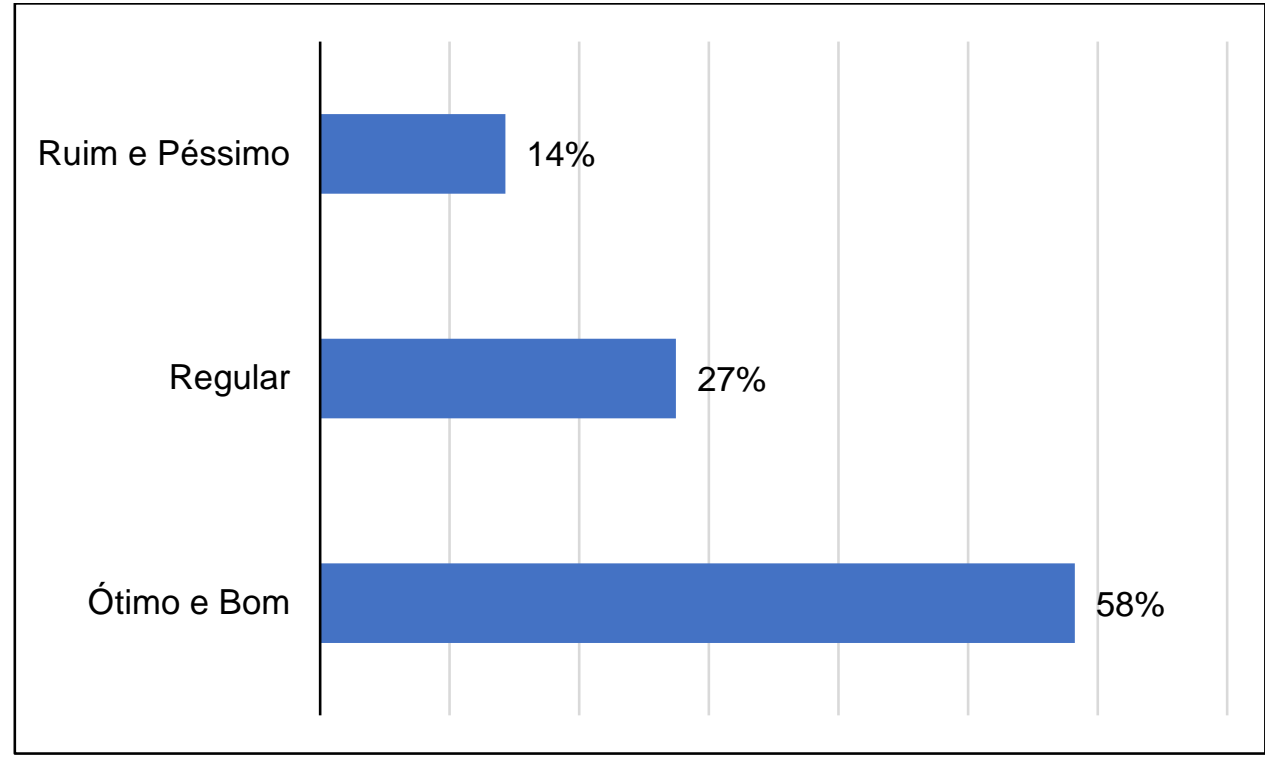

Fonte: Autor (2021).

\subsection{Adaptação ao estilo das aulas remotas}

Frente ao desafio de adaptação às aulas remotas existente no cenário atual, as Instituições de Ensino Superior, como a POLI/UPE, se debruçaram na aposta do diálogo visando o esclarecimento e a melhoria para proporcionar uma adaptação mais favorável. A exemplo disso, cita-se as ações de lives efetuadas, ou seja, encontros virtuais proporcionados pela Coordenação Setorial de Graduação no início do período para esclarecer a proposta e as dúvidas do PLS. Além disso, ressalta-se o esclarecimento e acompanhamento contínuo dos ingressantes durante o período por parte dos tutores.

Diante dos dados analisados na Figura 4, acerca da adaptação ao estilo das aulas remotas, nota-se que $56,04 \%$, do percentual total dos ingressantes, classificaram como "Ótimo e Bom". Em contrapartida, apenas $14,28 \%$ dos alunos classificam a adaptação como "Ruim e Péssima". Por meio desse registro, existe uma favorável adaptação ao estilo das aulas remotas. 


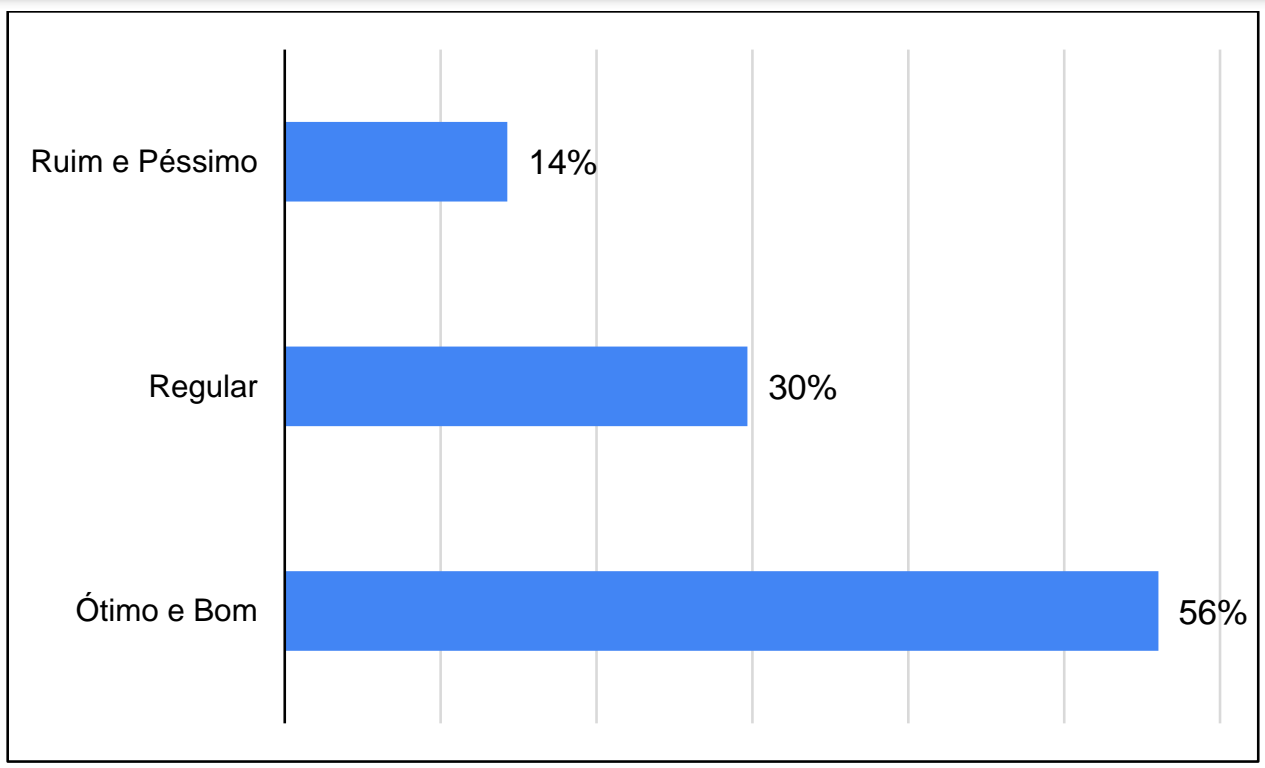

Fonte: Autor (2021).

\subsection{Aproveitamento acadêmico}

\subsubsection{Análise do aproveitamento das disciplinas vivenciadas}

Tendo em vista o reconhecimento das dificuldades encontradas no ensino remoto, como dispor de aparelhos eletrônicos e dados de internet, a UPE concebeu o auxílio de inclusão digital. Esse adjutório inclui um pacote de dados móveis para os estudantes que se encontram em condições de vulnerabilidade econômica, auxiliando no acesso às disciplinas e melhor aproveitamento das mesmas.

Diante da avaliação do aproveitamento das disciplinas vivenciadas, correspondente a Figura 5, pode-se constatar de forma geral que $49,45 \%$ dos ingressantes classificaram como "Ótimo e Bom". No mesmo grupo de amostra, 34,06\% dos ingressantes apontaram que julgam o aproveitamento como "Regular" e, apenas, $16,48 \%$ avaliam o aproveitamento das disciplinas vivenciadas como "Ruim e Péssimo". Portanto, com base nos dados, o aproveitamento das disciplinas nos quais os ingressantes experienciaram durante o PLS se expressou de maneira satisfatória. 
Figura 5: Avaliação do aproveitamento das disciplinas vivenciadas

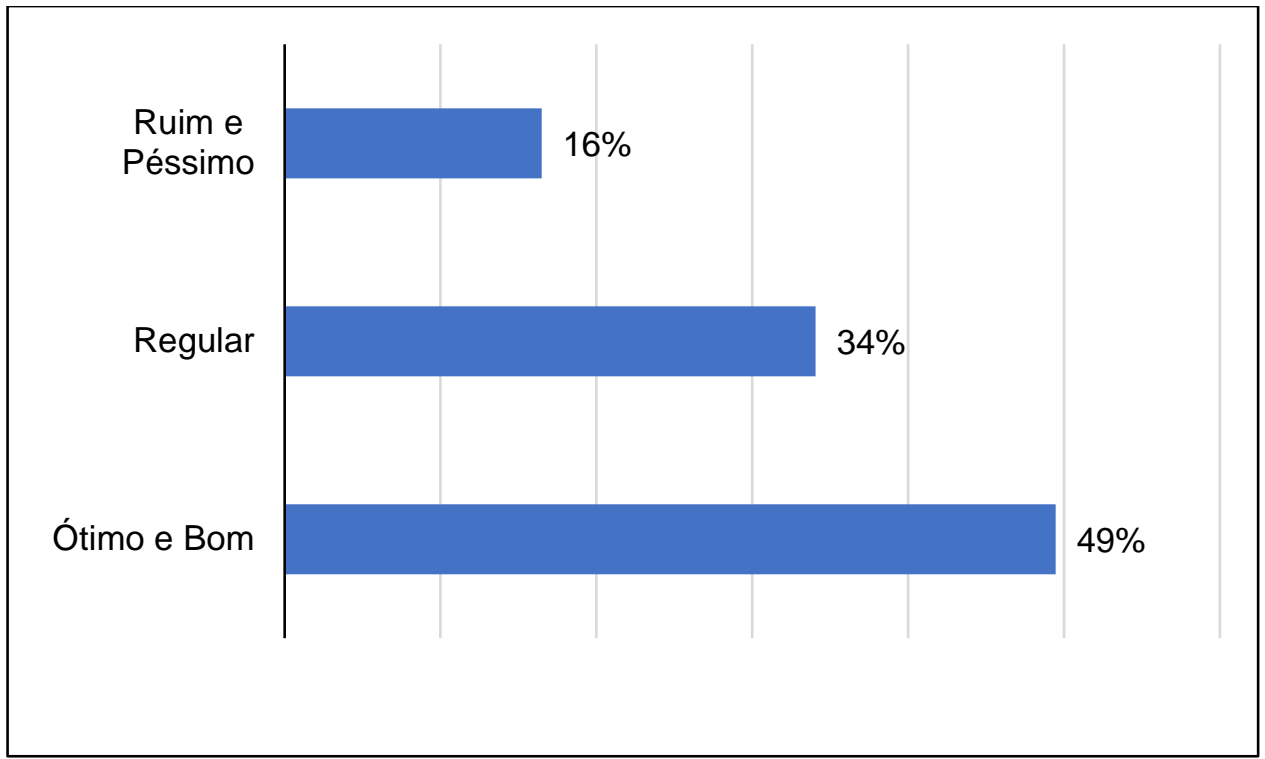

Fonte: Autor (2021).

\subsubsection{Análise do aproveitamento do desempenho em relação as disciplinas cursadas}

Referente ao aproveitamento acadêmico do estudante no Período Letivo Suplementar (PLS), a Resolução CEPE N 058/2020 admitiu que a reprovação em componentes curriculares não seria contabilizada no histórico do discente para efeito de acompanhamento/desligamento do curso (UPE, 2020).

Acerca dessa temática e da análise dos dados expostos na Figura 6, referente ao aproveitamento do desempenho em relação às disciplinas cursadas por parte dos ingressantes no PLS, pode-se certificar que $65 \%$ dos ingressantes classificam como "Ótimo e Bom", apresentando um desempenho satisfatório para a maioria. Com isso, se ressalta o caráter positivo do ensino remoto. 
Figura 6: Avaliação do desempenho das disciplinas cursadas

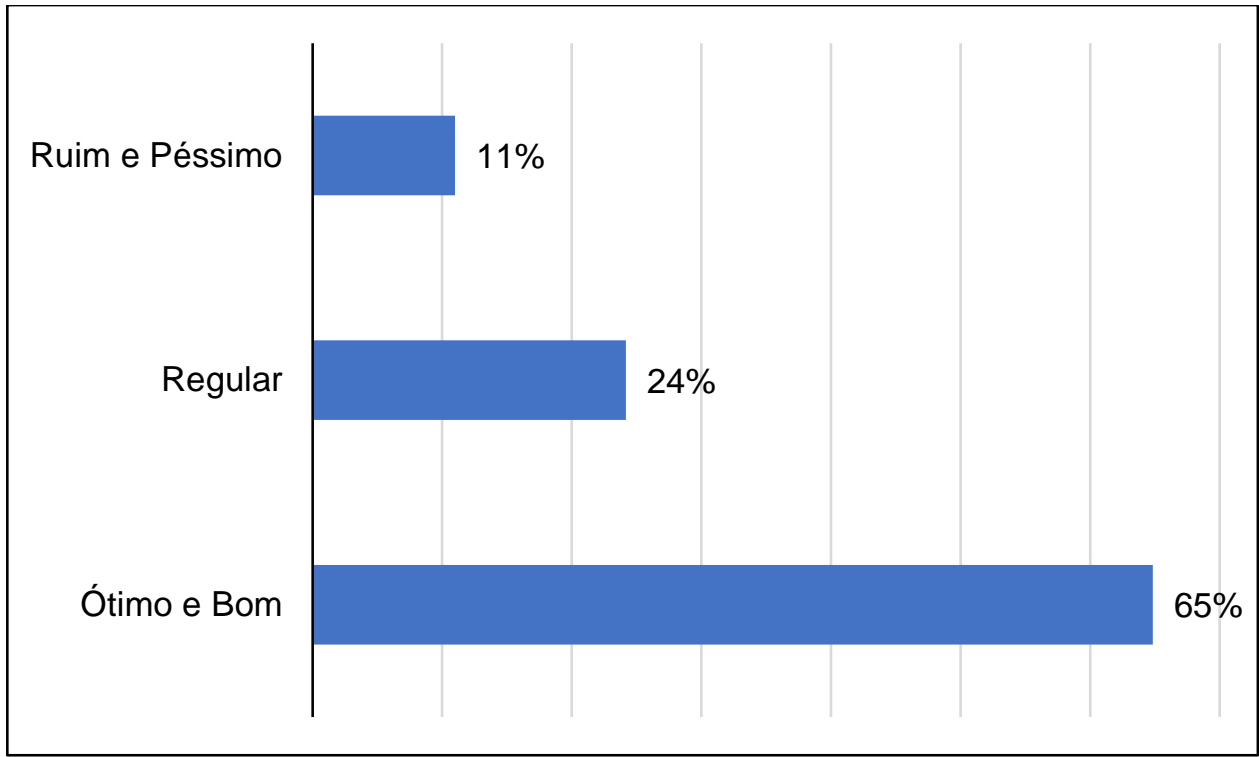

Fonte: Autor (2021).

\section{CONSIDERAÇÕES FINAIS}

Esta pesquisa propôs, como objetivo geral, identificar e acompanhar os aspectos que caracterizam o desenvolvimento acadêmico do ingressante da POLI durante o PLS, através da viabilização do Projeto Padrinhos. O Projeto, implantado em 2012 tem promovido o acolhimento, integração e orientação aos ingressantes e durante a situação pandêmica instalada, busca minimizar os desafios resultante das propostas pedagógicas planejadas para atender a atual demanda.

A partir da avaliação identificada no estudo, algumas categorias mostraram-se satisfatórias, tanto para o aproveitamento acadêmico em relação às disciplinas cursadas quanto para adaptação ao estilo da aula remota e a comunicação com os professores e colegas. Estes resultados evidenciam que apesar dos desafios e das dificuldades, o Período Letivo Suplementar (PLS) atuou de forma satisfatória no andamento acadêmico para a maioria dos ingressantes.

Destaca-se, ainda, que a coordenação do Projeto Padrinhos busca impreterivelmente a melhoria das ações, ferramentas e análises de dados para 0 aperfeiçoamento do Projeto que vem sendo construído, a todo momento, desde 2012, para os ingressantes e com os estudantes veteranos.

\section{Agradecimentos}

Dedicamos esta parte do trabalho para gratular a todos os membros do Projeto Padrinhos, incluindo primordialmente os ingressantes que confiaram no Projeto. Agradecemos ainda aos coordenadores do NAPSI, de forma singular a coordenadora pedagoga por planejar, acreditar e construir com os alunos o Projeto Padrinhos desde 2012. Registra-se, também, a gratidão a Escola Politécnica da Universidade de Pernambuco e ao 
senhor José Roberto de Souza Cavalcanti, o diretor da POLI/UPE, por confiarem e assistirem todas as ações desenvolvidas pelo Projeto.

\section{REFERÊNCIAS}

CUNHA, Simone Miguez; CARRILHO, Denise Madruga. O processo de adaptação ao ensino superior e o rendimento acadêmico. Psicologia escolar e educacional, v. 9, n. 2, p. 215-224, 2005.

\section{ESCOLA POLITÉCNICA DA UNIVERSIDADE DE PERNAMBUCO. Relatório de}

Atividades da Gestão 2014 - 2018, p. 5, 2018. Disponível em:

http://upe.poli.br/relatorios-de-atividades/. Acesso em: 06 mai. 2021.

GOLEMAN, D. Inteligência emocional. Rio de Janeiro: Objetiva, 2012

MANZATO, Antonio José; SANTOS, Adriana Barbosa. A elaboração de questionários na pesquisa quantitativa. Departamento de Ciência de Computação e Estatística-

IBILCE-UNESP, $\quad$ p. $\quad 1-17, \quad 2012 . \quad$ Disponível
http://www.abenge.org.br/sis artigo doi.php?e=COBENGE\&a=20\&c=2886. Acesso em 15 abr. 2021.

MARTINS, Vivian; ALMEIDA, Joelma. EDUCAÇÃO EM TEMPOS DE PANDEMIA NO BRASIL: SABERESFAZERES ESCOLARES EM EXPOSIÇÃO NAS REDES. Revista Docência e Cibercultura, [S.I.], v. 4, n. 2, p. 215-224, ago. 2020. ISSN 2594-9004.

Disponível em: <https://www.e-publicacoes.ueri.br/index.php/re-doc/article/view/51026>. Acesso em: 09 maio 2021

NETO, Hamilton C. D. F. et al. Projeto Padrinhos: acolhimento, integração e orientação para os estudantes ingressantes da escola politécnica da universidade de pernambuco. In: XLVIII Congresso Brasileiro de Educação em Engenharia, 2020, On-line. Anais. Online. Disponível em:

http://www.abenge.org.br/sis artigo doi.php?e=COBENGE\&a=20\&c=2886. Acesso em 15 abr. 2021.

RICOLDI, Arlene; ARTES, Amélia. Mulheres no ensino superior brasileiro: espaço garantido e novos desafios. Ex aequo, n. 33, p. 149-161, 2016.

UNIVERSIDADE DE PERNAMBUCO. RESOLUÇÃO CEPE № 058/2020, 2020. Disponível em: https://drive.google.com/file/d/1AEyoH LZxj mg4JNJcJqQr40WY2A9os/view. Acesso em 17 abr. 2021.

VIEIRA, L.; RICCI, M.C.C. A educação em tempos de pandemia: soluções emergenciais pelo mundo. OMESC. Disponível em:

https://www.udesc.br/arquivos/udesc/id cpmenu/7432/EDITORIAL DE ABRIL Let c ia Vieira e Maike Ricci final 15882101662453 7432.pdf Acesso em: 09 mai. 2021

ZAMBIANCO,D. DI Pietro. As competências socioemocionais: 
pesquisa bibliográfica e análise de programas escolares

sob a perspectiva da psicologia moral.2017. Tese (Doutorado) - Curso de Educação.

Universidade Estadual de Campinas, São Paulo, 2020. Disponível em: http://repositorio.unicamp.br/jspui/bitstream/REPOSIP/343284/1/Zambianco DanilaDiPiet ro M.pdf Acesso em; 05 mai. 2021.

\title{
PROJETO PADRINHOS IN PERÍODO LETIVO SUPLEMENTAR OF THE ESCOLA POLITÉCNICA DE PERNAMBUCO - AVALUATION OF INGRESSING STUDENT
}

\begin{abstract}
The article presents a study of the trajectory of those new students the Escola Politécnica da Universidade de Pernambuco in the Período Letivo Suplementar (PLS). Through the feasibility of the Projeto Padrinhos, it was possible to carry out the study that aims to identify aspects evaluated by the incoming student that characterize his academic performance during the PLS. Exploratory in nature, the research included the use of a form, which was made available online through the 'Google Forms' platform. 91 new student who chose to enroll in the disciplines offered by the respective engineering courses participated. The questions that mobilized the form were structured in 5 categories: personal data, courses taken, communication, adaptation and use. As a result: 29 new students are female, while 62 are male; in relation to the courses taken, it was found that 64 new students enrolled in at least 4 subjects; it is also observed that 53 new students registered effective communication with the class and teachers; and that 51 new students positively evaluated the adaptation to the style of the remote classes; in accordance with academic achievement, 45 new students satisfactorily conceptualized the disciplines they experienced and 59 new students evaluated the courses taken in a profitable way. Even with the pioneering spirit and the particularity of PLS, this study indicates a satisfactory use of the academic period, despite being considered as challenging. Regarding the feasibility of the Projeto Padrinhos in a context of physical distance, the coordination notes its relevance for channeling the efforts of the veterans involved in guaranteeing the reception, integration and orientation to the new student.
\end{abstract}

Keywords: Reception. Academic achievement. Incoming. Integration. Período Letivo Suplementar. 